\title{
Fortalezas abandonadas, saqueadas, redescobertas, restauradas, patrimonializadas: da democratização à pluralização do patrimônio
}

\section{Fortresses that were abandoned, looted, rediscovered, restored, patrimonialized: from democratization to the pluralization of cultural heritage}

\author{
Pedro Mülbersted Pereira ${ }^{1}$ \\ Elison Antonio Paim²
}

Resumo: As fortalezas de Anhatomirim, Ratones e Ponta Grossa, localizadas na região da Grande Florianópolis (SC), são bens culturais tombados pelo Sphan (hoje, Iphan) desde 1938, e tutelados pela Universidade Federal de Santa Catarina (UFSC) desde 1979 e 1991, respectivamente. A UFSC empreendeu uma série de ações para a construção de uma memória histórica acerca do processo de patrimonialização destes bens culturais, que, somado aos usos dados a estes bens, geram adesões e não-adesões em torno do patrimônio. $\mathrm{O}$ presente artigo analisa como os agentes sociais envolvidos neste processo construíram uma memória acerca das fortalezas, identificando as estratégias discursivas de alguns destes agentes a partir das suas narrativas em entrevistas, matérias jornalísticas e documentos oficiais produzidos pela UFSC; problematizamos as concepções de história e patrimônio presentes nestes discursos a partir da perspectiva teórica de Walter Benjamin na relação com seus interlocutores, bem como Chagas (2002), Fonseca (2009), Chuva (2009), Pereira e Oriá (2012), Galzerani (2008, 2013) para relacionarmos com o campo do patrimônio no Brasil, a fim de avançarmos no debate da democratização para a pluralização do patrimônio.

Palavras-chave: fortalezas catarinenses, memória, democratização do patrimônio.

\begin{abstract}
The three Fortress Anhatomirim, Ratones and Ponta Grossa are located in the Grande Florianópolis mesoregion, and are preserved as cultural assets by the Sphan (Iphan, nowadays) since 1938, and protected by the Federal University of Santa Catarina (UFSC) from 1979 and 1991, respectively. There are a lot of actions taken by UFSC in the purpose of creating a historical memory of the patrimonialization process of these assets, making adhesions and non-adhesions around the cultural heritage. The present article analyzes how the social agents involved in this process built a memory about the fortresses. We identify the discursive strategies of some of these agents from their narratives in interviews, journalistic materials and official documents produced by UFSC; we problematize the concepts of History and Cultural Heritage in these discourses from the theoretical view of Walter Benjamin, in relation within his associates, as well as Chagas (2002), Fonseca (2009), Chuva (2009), Pereira e Oriá (2012), Galzerani $(2008,2013)$ to discuss the cultural heritage field in Brazil, so we can advance from the democratization to the pluralization of cultural heritage.
\end{abstract}

Keywords: democratization of cultural heritage, memoir, Santa Catarina fortresses.

\footnotetext{
${ }^{1}$ Doutorando pelo Programa de Pós-Graduação em Educação da Universidade Federal de Santa Catarina (PPGE - UFSC). Email: pedro.mulbersted@gmail.com

2 Doutor em História. Professor Adjunto da Universidade Federal de Santa Catarina (UFSC), lotado no Departamento de Metodologia de Ensino (MEN) do Centro de Educação. E-mail: elison0406@gmail.com
} 


\section{Introdução}

Em 05 de novembro de 2017, domingo, a Universidade Federal de Santa Catarina (UFSC) realizou a Abertura da Temporada de Verão nas Fortalezas, programação que teve espaço nas três fortalezas tuteladas por esta universidade: a Fortaleza de Santa Cruz de Anhatomirim, Fortaleza de Santo Antônio de Ratones e Fortaleza de São José da Ponta Grossa. ${ }^{3}$ A programação deste evento foi divulgada no site da UFSC:

A Universidade Federal de Santa Catarina (UFSC) comemora a Abertura da Temporada de Verão nas Fortalezas, com shows musicais, trajes de época, combate medieval e muita diversão. A abertura será no dia 5 de novembro, a partir das $9 \mathrm{~h}$, com entrada gratuita. Entre as atrações estão a Orquestra de Choro do Campeche, Banda da $14^{\circ}$ Brigada de Infantaria Motorizada, Chiqueti \& Banda, Sociedade Histórica Destherrense, SCAM - Arquearia e combate medieval e o Boi de Mamão de Santo Antônio. As atrações serão realizadas na Fortaleza de São José da Ponta Grossa, na Praia do Forte, das $10 \mathrm{~h}$ às $17 \mathrm{~h}$. No mesmo dia, todas as fortalezas sob gestão da UFSC estarão com acesso livre. ${ }^{4}$

A Universidade informa que a abertura é uma iniciativa da "Coordenadoria das Fortalezas da Ilha de Santa Catarina (CFISC), vinculado à Secretaria de Cultura e Arte (SeCArte) da UFSC” em parceria com o "Governo do Estado de Santa Catarina, Secretaria de Estado e Turismo, Cultura e Esporte, Fundação Catarinense de Cultura, e da Prefeitura Municipal de Florianópolis, Secretaria Municipal de Cultura, Esporte e Juventude e Fundação Franklin Cascaes".

A programação foi divulgada também em outros meios, como a Revista Museu ${ }^{5}$ e o jornal Notícias do $\mathrm{Dia}^{6}$. Este último informava que o evento era "organizado pela

\footnotetext{
${ }^{3}$ Estas fortificações foram construídas no século XVIII (1739-1743), projetadas por José da Silva Paes, brigadeiro, engenheiro militar e primeiro governador da capitania de Santa Catarina. Estas fortalezas deram início ao sistema defensivo da Ilha de Santa Catarina, que, posteriormente, foi acrescido com outros fortes, fortins, baterias, trincheiras. A partir da primeira metade do século XIX, este sistema defensivo é ressignificado, assume outras funções, e, em decorrência, a maioria destas construções foram desativadas, abandonadas, arruinaram-se e desapareceram; as fortificações que permaneceram ativas até o século XX encontravam-se em péssimo estado de conservação, até a década de 1970. Em 1938, as fortalezas de Anhatomirim, Ratones e Ponta Grossa e o Forte de Santana do Estreito foram tombadas como patrimônio histórico brasileiro pelo Serviço do Patrimônio Histórico e Artístico Nacional (SPHAN, hoje Iphan). A partir de fins da década de 1960, iniciou-se o restauro do Forte Santana da Fortaleza de Anhatomirim, e, nos anos 1990, a Fortaleza de Ratones e a Fortaleza da Ponta Grossa. ${ }^{4}$ ABERTURA da Temporada de Verão nas Fortalezas da UFSC com atrações culturais e entrada gratuita. Notícias da UFSC, online, 31 out 2017. Disponível em: <http://noticias.ufsc.br/2017/10/abertura-da-temporadade-verao-nas-fortalezas-da-ufsc-com-atracoes-culturais-e-entrada-gratuita/>. Acesso em: 09 jan 2018.

${ }^{5}$ ABERTURA da Temporada de Verão nas Fortalezas da UFSC. Revista Museu: cultura levada a sério, online, 04 nov. 2017. Disponível em: <https://www.revistamuseu.com.br/site/br/o-escriba/3670-04-11-2017-abertura-datemporada-de-verao-nas-fortalezas-da-ufsc.html>. Acesso em: 09 jan 2018.

${ }^{6}$ FORTALEZA de São José da Ponta Grossa terá atrações especiais no domingo em Florianópolis. Notícias do Dia, online, 31 out 2017. Disponível em: <https://ndonline.com.br/florianopolis/noticias/fortaleza-de-sao-joseda-ponta-grossa-tera-atracoes-especiais-no-domingo-em-florianopolis>. Acesso em: 09 jan 2018.
} 
Coordenadoria das Fortalezas da Ilha de Santa Catarina, vinculada à Secretaria de Cultura e Arte da UFSC (Universidade Federal de Santa Catarina), em comemoração à abertura da temporada de verão nas fortalezas", contando com o "apoio do Governo do Estado de Santa Catarina e da Prefeitura Municipal de Florianópolis"; destacava também que esta programação marcava o "Dia Nacional da Cultura, celebrado em 5 de novembro", e também o "último Dia de Gratuidade nas fortalezas em 2017”.

Esta é uma das ações empreendidas pela UFSC, no ano de 2017, com o objetivo de dinamizar o uso das fortalezas sob sua tutela. Este objetivo fica expresso, também, entre as dicas que seguem à programação do evento - em uma destas, sugere-se: "tire fotos à vontade e poste com nossas hashtags \#QueroCultura \#EuValorizoAsFortalezas", 7 sinalizando uma intenção de valorização do patrimônio cultural através das redes sociais.

Estas publicações jornalísticas celebram a iniciativa da UFSC com esta programação, e dão visibilidade para a gestão desta para com as três fortalezas. Há, também, um discurso que naturaliza a patrimonialidade das fortalezas e relação destes monumentos com a cultura. As fortalezas são apresentadas como um local de visitação turística onde é possível conciliar cultura e lazer, fazendo destas uma das atrações da temporada de verão no litoral catarinense. ${ }^{8}$

Entretanto, outras notícias veiculadas na imprensa catarinense dão um outro tipo de visibilidade para a UFSC e as fortalezas.

Em 2013, o jornal Notícias do Dia informava seus leitores sobre um impasse na região da Praia do Forte, entorno da Fortaleza de São José da Ponta Grossa, envolvendo a ordem de demolição expedida para dois imóveis considerados irregulares na região - um destes imóveis divisa a muralha da dita fortaleza. Segundo o jornal, a universidade tinha interesse na demolição do imóvel pois o terreno deveria ser destinado para a "recepção dos visitantes e colocação de acessos a portadores de deficiência ao edifício histórico" - o que já vinha sendo cobrado pelo Ministério Público, de acordo com o jornal.

Assim o jornal constrói a trama sobre o impasse:

\footnotetext{
${ }^{7}$ ABERTURA da Temporada de Verão nas Fortalezas da UFSC com atrações culturais e entrada gratuita. Notícias da UFSC, online, 31 out 2017. Disponível em: <FORTALEZA de São José da Ponta Grossa terá atrações especiais no domingo em Florianópolis. Notícias do Dia, online, 31 out 2017. Disponível em: $<$ https://ndonline.com.br/florianopolis/noticias/fortaleza-de-sao-jose-da-ponta-grossa-tera-atracoes-especiais-nodomingo-em-florianopolis>. Acesso em: 09 jan 2018.>.

${ }^{8}$ Os jornais catarinenses desempenharam um papel fundamental na construção da imagem da fortaleza de Anhatomirim como uma atração turística onde lazer e cultura se encontram, por reunir, em um mesmo espaço, um monumento histórico restaurado à praia e ao mar, durante o processo de patrimonialização desta fortaleza (PEREIRA, 2016).
} 
Sondando os diferentes agentes envolvidos no imbróglio, incluindo a SPU (Superintendência do Patrimônio da União), percebe-se que ninguém quer assumir o ônus das demolições, pelo temor de criar um conflito de grandes proporções com a comunidade, formada por antigos moradores, famílias que chegaram depois e empreendedores que conseguiram autorização para erguer pousadas, mansões ou chalés na região. Depois que o Exército saiu dali, em meados da década de 1950, a área da fortaleza ficou abandonada, o que estimulou as invasões. ${ }^{9}$

$\mathrm{O}$ jornal entrevistou alguns agentes vinculados à Universidade Federal de Santa Catarina, dentre estes, Joi Cletison Alves, historiador ligado ao Projeto Fortalezas da Ilha de Santa Catarina. Neste trecho da matéria jornalística, o mesmo justifica o interesse da universidade na demolição do referido imóvel:

A Universidade só tem interesse em remover a casa que fica ao lado da parede do forte", diz Joi Alves, explicando que o caseiro da fortaleza vem sendo impedido de retirar a vegetação dos embrechamentos e, com isso, evitar a deterioração das muralhas. "A outra ação envolvendo moradores tradicionais não nos diz respeito. ${ }^{10}$

Carlos Vieira, então chefe de gabinete da reitoria da UFSC, afirmou: "Não queremos atrito com pessoas genuínas da região"; o mesmo também considerou que "a Justiça é que deve decidir sobre o que fazer, e à SPU cabe executar o que for resolvido".

Para Roberto Tonera"11, a universidade "não deveria ter receio de enfrentar um mal-estar com a comunidade":

O arquiteto explica que os 185 mil metros quadrados do morro onde está a fortaleza pertencem à União (ainda estão jurisdicionados ao Exército) e não dão direito de usucapião aos ocupantes dos terrenos. A área da UFSC tem menos de 18 mil metros, e fotos aéreas nas mãos da instituição mostram que o processo de ocupação das encostas cresceu muito em poucas décadas. Os moradores contam apenas com um contrato de gaveta, um título precário de uso, pelo qual pagam o laudêmio, uma espécie de aluguel. "Contudo, eles vendem a terceiros como se fosse deles", informa Roberto Tonera. "A União pode solicitar a devolução dos terrenos a hora que quiser".

Como não há mais margem para apelações, e como o mandado de execução da sentença demolitória já saiu, o arquiteto não vê chance de reversão do quadro. "Houve épocas em que havia até gente morando dentro da fortaleza”, conta. Ao contrário do

\footnotetext{
${ }^{9}$ IMPASSE na fortaleza de São José da Ponta Grossa. Jurerê. Ninguém tem coragem de fazer a demolição de construções irregulares pedida pela Justiça no Norte da Ilha. Notícias do Dia [online], 11 ago 2013. Disponível em: <https://ndonline.com.br/florianopolis/noticias/impasse-na-fortaleza-de-sao-jose-da-ponta-grossa>. Acesso em: 09 jan 2018.

${ }^{10}$ IMPASSE na fortaleza de São José da Ponta Grossa. Jurerê. Ninguém tem coragem de fazer a demolição de construções irregulares pedida pela Justiça no Norte da Ilha. Notícias do Dia [online], 11 ago 2013. Disponível em: <https://ndonline.com.br/florianopolis/noticias/impasse-na-fortaleza-de-sao-jose-da-ponta-grossa>. Acesso em: 09 jan 2018.

${ }^{11}$ Roberto Tonera é arquiteto, servidor da UFSC; participou do processo de restauro das fortalezas na década de 1990. É coordenador do Projeto "Fortalezas Multimídia”, projeto de extensão da UFSC, desde 1995. Nesta matéria jornalística, é apresentado como "do Dpae (Departamento de Projetos de Arquitetura e Engenharia da UFSC)" e como "colega no Projeto Fortalezas" de Joi Cletison Alves.
} 
uruguaio da pousada, que seguiu os trâmites normais, muitos moradores (incluindo Euclides e filhos) teriam agido à revelia da lei. O uso da área, independente da duração, também não dá direito de indenização em caso de devolução ao seu proprietário, que é a União. ${ }^{12}$

O jornal publicou também a posição do Iphan, representado por Virgínia Gomes de Luca, "chefe da Divisão Técnica do Iphan/SC" e Cristiane Galhardo Biazin, "técnica”. O Iphan se posicionava "favoravelmente às demolições decretadas pelo judiciário" justificando que a maior parte dos casos referiam-se a "construções feitas de forma irregular no entorno imediato da fortaleza (de acordo com o artigo $n^{\circ} 18$ do decreto-lei $n^{\circ}$ 25/1937, que proíbe qualquer edificação e colocação de anúncios ou cartazes na vizinhança de prédios tombados que impeçam ou reduzam a sua visibilidade)"; de acordo com a matéria jornalística, o Iphan admitia que "foi solicitado a derrubar a casa, mas entende que a área está sendo requerida pela UFSC para implantar os equipamentos de acessibilidade e que, portanto, cabe a esta a tarefa, já que o proprietário não providenciou a demolição". ${ }^{13}$

O jornal também apresentou a versão de moradores da comunidade da Praia do Forte:

Ivânio Alves da Luz, 56 anos, dono de um pequeno restaurante na estrada que dá acesso à fortaleza de São José da Ponta Grossa, é enfático ao dizer que os antigos moradores da área é que foram invadidos quando surgiram as fortificações para a proteção da entrada norte da Ilha de Santa Catarina, na primeira metade do século 18. "Quando o Exército chegou, já havia famílias aqui", afirma.

[...] "Com o grande número de liberações para obras aqui, por que querem tirar uma comunidade tão tradicional?", pergunta, ressaltando que há casas de quase 300 anos resistindo na região. "Nascemos e queremos morrer aqui", conclui. Ele defende um plano diretor específico para a praia do Forte, integrando a fortaleza e a comunidade do entorno.

$[\ldots]$

Neusa Alves da Luz, irmã de Ivânio, mantém o Quiosque do Forte ainda mais perto da entrada da fortaleza e dispara contra a UFSC em todas as frases que pronuncia. Para ela, a Universidade explora os turistas ao cobrar $\mathrm{R} \$ 8$ pela entrada na fortificação e não tem o direito de derrubar a casa de Amilton Jovino dos Santos, que funcionou como cozinha da fortaleza durante muitos anos. Ela está convencida de que "o pessoal de Jurerê" quer tomar conta da área. ${ }^{14}$

\footnotetext{
${ }^{12}$ IMPASSE na fortaleza de São José da Ponta Grossa. Jurerê. Ninguém tem coragem de fazer a demolição de construções irregulares pedida pela Justiça no Norte da Ilha. Notícias do Dia [online], 11 ago 2013. Disponível em: <https://ndonline.com.br/florianopolis/noticias/impasse-na-fortaleza-de-sao-jose-da-ponta-grossa>. Acesso em: 09 jan 2018.

${ }^{13}$ IMPASSE na fortaleza de São José da Ponta Grossa. Jurerê. Ninguém tem coragem de fazer a demolição de construções irregulares pedida pela Justiça no Norte da Ilha. Notícias do Dia [online], 11 ago 2013. Disponível em: <https://ndonline.com.br/florianopolis/noticias/impasse-na-fortaleza-de-sao-jose-da-ponta-grossa>. Acesso em: 09 jan 2018.

${ }^{14}$ IMPASSE na fortaleza de São José da Ponta Grossa. Jurerê. Ninguém tem coragem de fazer a demolição de construções irregulares pedida pela Justiça no Norte da Ilha. Notícias do Dia [online], 11 ago 2013. Disponível em: <https://ndonline.com.br/florianopolis/noticias/impasse-na-fortaleza-de-sao-jose-da-ponta-grossa >. Acesso em: 09 jan 2018.
} 
Em 2011, este mesmo jornal já noticiava que a construção de um muro de pedras em uma propriedade próxima à fortaleza gerou indignação na comunidade. A construção teria sido "idealizada por um estrangeiro, que comprou dois terrenos, um deles com ligação para a rua localizada acima do forte", e já haviam começado "há cerca de dois meses, segundo moradores do local". A indignação por parte da comunidade se deve ao fato de que a obra teria sido autorizada pelo Iphan. O jornal cita Ivânio Alves da Luz - apresentado como comerciante e alguém que "faz parte do Condema (Conselho Municipal de Defesa do Meio Ambiente)":

Segundo o comerciante, Ivanio Alves da Luz, toda obra feita em casas próximas à Fortaleza são embargadas. "Há uma determinação que impede até reformas em nossas casas, aí chega um estrangeiro, constrói uma rua e faz um muro ao lado da Fortaleza? Quando um pescador quer arrumar seu rancho não pode. O Iphan tem que se explicar", desabafa. ${ }^{15}$

Para além das questões jurídicas e dos valores sociais e econômicos envolvidos, percebemos que existem disputas de memória neste impasse em torno da Fortaleza de São José da Ponta Grossa e da Praia do Forte. São disputas pelo uso de um espaço que comporta diferentes identidades: uma, construída pelas memórias e experiências da comunidade, e outra, construída com base na historiografia catarinense, conferindo um valor histórico a estes monumentos (PEREIRA, 2016). Nestas disputas estão em jogo diferentes valores, sentidos e significados para o patrimônio.

A população que vive no entorno destas fortalezas historicamente foi alijada de participar deste processo de patrimonialização, desde a escolha e seleção destes bens para serem tombados, na década de 1930, até a restauração destes monumentos nas décadas de 1970 a 1990. Assim, os critérios técnicos (e políticos) adotados nestas iniciativas do poder público desconsideraram estes sujeitos - bem como os seus saberes - de modo que o patrimônio valorizado não correspondia diretamente ao patrimônio sentido, percebido, vivido por esta população.

O processo de patrimonialização das fortalezas catarinenses foi possível a partir da articulação de uma série de estratégias por parte de agentes sociais, mobilizados como uma rede de sociabilidades em torno das fortalezas catarinenses. Estes agentes partilhavam lugares sociais comuns, saberes, valores e sensibilidades sobre o patrimônio, tornando, assim, possível, aderirem a uma campanha em prol do restauro destes monumentos, que buscou sensibilizar

\footnotetext{
${ }^{15}$ ESTRANGEIRO constrói muro de pedras e rua ao lado da Fortaleza de São José da Ponta Grossa. Notícias do Dia, online, 14 jul 2011. Disponível em: <https://ndonline.com.br/florianopolis/noticias/estrangeiro-constroimuro-de-pedras-e-rua-ao-lado-da-fortaleza-de-sao-jose-da-ponta-grossa>. Acesso em; 09 jan 2018.
} 
setores específicos da sociedade catarinense e brasileira: diretores de órgãos estatais, empresários, militares, governadores, prefeitos, reitores e professores universitários e intelectuais, bem como a mídia catarinense (PEREIRA, 2016; MARTINS, GONZAGA, 2017).

Estes agentes sociais também investiram na construção de uma memória sobre as fortalezas catarinenses - uma memória de valorização do patrimônio, em detrimento a uma memória de abandono, arruinamento e destruição destes bens. Estes agentes se reconhecem como sujeitos históricos a medida que atuaram no restauro, na preservação e na valorização destes bens culturais, garantindo, assim, a inscrição de seus nomes nesta história, enquanto que atribuem aos moradores das comunidades do entorno destas fortalezas a pecha de ameaça a estes bens e à própria História, identificando-os como um dos agentes que contribuíram para o arruinamento destas construções.

Apresentamos neste artigo as adesões e não-adesões ao processo de patrimonialização das fortalezas catarinenses ${ }^{16}$ através da construção de uma memória histórica sobre este processo. Analisamos como a Universidade Federal de Santa Catarina (UFSC) consolida uma dada memória sobre o processo de patrimonialização das fortalezas catarinenses que privilegia a atuação de agentes vinculados a esta instituição e parceiras, e, por outro lado, invisibiliza e exclui outros grupos e sujeitos, bem como outras memórias sobre estas fortalezas.

O discurso sobre a ruína é uma das práticas discursivas mobilizadas para excluir outras narrativas, memórias, histórias, identidades que não sejam identificados com a cultura, subalternizando-os como a barbárie (BENJAMIN, 2012). Identificamos este discurso a partir de narrativas que estão presentes em documentos da universidade (UFSC, 2014), bem como produções bibliográficas e outras (TONERA, 2001, 2005; MACHADO, 1992) e através de publicações na imprensa catarinense. Analisamos também as memórias dos arquitetos que participaram do processo de restauro destas fortalezas: Cyro Lyra, Dalmo Vieira Filho, e José de La Pastina Filho. Selecionamos entrevistas com Cyro Lyra e Dalmo Vieira Filho em 1990, durante a segunda fase do processo de patrimonialização destas fortalezas com o Projeto Fortalezas da Ilha de Santa Catarina: 250 anos de História Brasileira (1989-1991), presentes no CD-Rom Fortalezas Multimídia (TONERA, 2001), e também as entrevistas com Cyro Lyra e com La Pastina realizadas por Celso Martins em 2015, publicadas na obra Memórias das

\footnotetext{
${ }^{16}$ Usamos o termo fortalezas catarinenses para nos referir às três fortalezas de Anhatomirim, Ratones e Ponta Grossa, para denominar as fortificações mantidas e tuteladas pela UFSC; entretanto, cabe salientar que existem outras fortificações no Estado de Santa Catarina: a Fortaleza de Nossa Senhora da Conceição de Araçatuba, o Forte Santana, o Forte Santa Bárbara, o Forte Marechal Moura - todas estas em Florianópolis - e o Forte Marechal Luz, em São Francisco do Sul.
} 
fortalezas - Ilha de Santa Catarina. No meio do caminho havia um Armando (MARTINS; GONZAGA, 2017). ${ }^{17}$

Entendemos que estas questões em torno das fortalezas catarinenses como patrimônio se relacionam com a discussão do filósofo Walter Benjamin sobre a condição de vencedores e vencidos na história, com "a tradição dos oprimidos" e sobre o conceito de história. O filósofo berlinense criticou as principais concepções de História do seu tempo para construir uma compreensão outra da História. Aproximamos as contribuições de Benjamin às de Delgado (2008), Fonseca (2009) e Chuva (2009) para arrazoar sobre as configurações do campo do patrimônio no Brasil, particularmente a concepção de História e Patrimônio articulada nas narrativas dos agentes sociais mencionados. Entendemos que este é um movimento necessário, pois, se estamos comprometidos com o uso social da memória, é mister ampliar a discussão sobre democratização do patrimônio para a pluralização do patrimônio, isto é, um movimento que gere novas adesões neste processo, que se contraponha às exclusões perpetradas neste processo.

\title{
O discurso sobre a ruína
}

Roberto Tonera (2005) afirma que as fortalezas catarinenses foram "redescobertas" no início da década de 1970; o primeiro passo foi dado pelo Iphan, com o restauro do Forte de Santana (ainda no final da década de 1960) e com o início das obras na Fortaleza de Anhatomirim. Entretanto,

\begin{abstract}
A história da recuperação das fortalezas alterou-se radicalmente a partir de 1979, quando a Universidade Federal de Santa Catarina assumiu a guarda e manutenção de Anhatomirim. A fortaleza foi aberta à visitação pública em 1984, após a restauração de grande parte de seus edifícios, numa ação conjunta com o IPHAN e a parceria de outras entidades públicas e privadas. No início da década de 1990, com patrocínio da Fundação Banco do Brasil, esta recuperação foi concluída, além de serem totalmente restauradas as fortalezas de Ratones e Ponta Grossa, também adotadas desde então pela Universidade, numa iniciativa pioneira e singular no Brasil (TONERA, 2005, p. 5).
\end{abstract}

Tonera se refere ao Projeto Fortalezas da Ilha de Santa Catarina: 250 anos de História Brasileira, que teve início em 1989 e foi financiado através de um convênio de cooperação

\footnotetext{
${ }^{17}$ Trata-se de uma obra que tem início com as memórias de Armando Gonzaga sobre a sua participação no processo de patrimonialização das fortalezas catarinenses, que vieram a ser somadas com as contribuições do jornalista Celso Martins. Gonzaga faleceu antes da conclusão e publicação da obra. Entendemos que esta obra é fundamental para compreender este processo a partir da ótica destes sujeitos, pois, para além do esforço autobiográfico, há uma estratégia de consolidação de uma dada memória histórica sobre o processo.
} 
financeira assinado entre a UFSC e a Fundação Banco do Brasil (FBB). A UFSC expressa em seu último Plano de Desenvolvimento Institucional (2015 - 2019) que este projeto foi criado "com o objetivo de restaurar e revitalizar as fortificações construídas pelos portugueses durante o século XVIII", e que o convênio firmado entre a UFSC e a FBB tinha como objetivo "a restauração e consolidação das fortificações de Santa Cruz de Anhatomirim, Santo Antônio de Ratones, São José da Ponta Grossa e Nossa Senhora da Conceição, localizadas na Barra Norte da Ilha de Santa Catarina"; afirma-se ainda neste documento que "os projetos de restauração foram elaborados em parceria com o IPHAN (Instituto do Patrimônio Histórico e Artístico Nacional) e a coordenação executiva da Universidade Federal de Santa Catarina” (UFSC, 2014, p. 52).

De acordo com Tonera (2005, p. 4), antes das intervenções do Iphan e da UFSC, "no final da década de 1960, as fortalezas de Anhatomirim, Ponta Grossa, Ratones e Araçatuba, além dos Fortes de Santana, Naufragados e Bateria de São Caetano encontravam-se em ruínas, entregues à ação da natureza e à depredação humana”. O arquiteto atribui esta situação de abandono e ruína a uma "somatória de causas interligadas", dentre as quais destacamos "o não reconhecimento pela sociedade de seu valor histórico e cultural (apesar de serem monumentos tombados nacionalmente)", e a "contínua falta de recursos para sua restauração; e a falta de uma instituição mantenedora que garantisse uma destinação contemporânea adequada para aquelas construções". Machado (1992, p. 27-28) apontava que a "indiferença pelos valores históricos, a ausência de uma política de preservação de bens culturais e a indisponibilidade de tecnologias e recursos humanos para intervenção em monumentos antigos" como algumas das causas para o estado de ruína em que estas fortificações se encontravam, em meados do século XX. Entretanto, este estado de coisas começara a mudar quando "uns poucos homens" olharam para estas fortalezas "com a esperança de reerguê-las":

Sozinhos, porém, a realização do sonho tornava-se difícil. Era necessária a participação de instituições que os auxiliassem. E assim se procedeu. A reunião de instituições, privadas ou estatais, com interesse os mais diversos, foi a mola-mestra para o início da revitalização das fortificações catarinenses. Partiu-se, assim, para a árdua tarefa de reedificar construções e conferir-lhes utilização permanente. (MACHADO, 1992, p. 121)

Para Machado (1992), portanto, a "revitalização das fortificações catarinenses" deveuse à "árdua tarefa" empreendida pela reunião de instituições públicas e privadas, a partir do olhar esperançoso de "uns poucos homens", isto é, os agentes sociais envolvidos no processo 
de patrimonialização das fortalezas catarinenses, como Armando Gonzaga ${ }^{18}$, Cyro Lyra ${ }^{19}$, Caspar Erich Stemmer, ${ }^{20}$ Rodolfo Pinto da Luz, ${ }^{21}$ Dalmo Vieira Filho, ${ }^{22}$ Maria de Lourdes Souza, ${ }^{23}$ e, ainda que indiretamente, Luis Saia, Oswaldo Rodrigues Cabral, Walter Piazza, entre outros. $^{24}$

Estes agentes sociais, ao narrarem as suas experiências no restauro das fortalezas catarinenses, construíram uma dada memória acerca deste processo. As memórias destes agentes sociais enfatizam, especialmente, o estado de arruinamento que estas fortalezas se encontravam antes do restauro: é o discurso sobre a ruína (PEREIRA, 2016). Este discurso é uma estratégia destes agentes com vias de justificar a participação das instituições a que estão vinculados no processo de patrimonialização das fortalezas catarinenses, bem como para afirmação do papel que cada um destes desempenhou neste processo, colocando a si mesmos como sujeitos históricos à medida que interviram para "resgatar" 25 estas fortalezas, identificados com o papel desempenhado pelas instituições as quais eram vinculados (a UFSC ou o Iphan, notoriamente).

O sentimento de que as fortalezas não tinham o seu valor histórico e cultural reconhecido por parte da sociedade fica expresso na narrativa de Cyro Lyra em entrevista a

\footnotetext{
${ }^{18}$ Armando Luiz Gonzaga é uma figura central no processo de patrimonialização das fortalezas catarinenses, considerado o responsável por articular os diferentes órgãos e instituições para tornar possível o restauro das fortalezas. Ver Celso Martins e Armando Gonzaga (2017).

${ }^{19}$ Cyro Corrêa Lyra é arquiteto e atuou no processo de restauro das fortalezas catarinenses. Sua empresa ARESTA - Arquitetura e Restauro fora contratada para as obras de restauro no Forte Santana e na Fortaleza de Anhatomirim, entre fins da década de 1960 até a década de 1980, bem como na consolidação das ruínas da Fortaleza de São José da Ponta Grossa. À época, era professor do curso de Arquitetura da Universidade Federal do Paraná (UFPR).

${ }^{20}$ Caspar Erich Stemmer era engenheiro, professor Titular da Universidade Federal de Santa Catarina (UFSC) do curso de Engenharia Mecânica desde 1962; foi diretor do Centro Tecnológico, chefe do Departamento de Engenharia Mecânica e reitor da Universidade Federal de Santa Catarina, entre 1976 e 1980. Faleceu em dezembro de 2012.

${ }^{21}$ Rodolfo Pinto da Luz foi reitor da Universidade Federal de Santa Catarina em 1984 a 1988, 1996 a 2000, 2000 a 2004. Foi presidente do Instituto de Planejamento Urbano de Florianópolis (IPUF) entre 1989 e 1990. Atua como secretário da Secretaria Municipal da Educação da Prefeitura Municipal de Florianópolis desde 2005.

${ }^{22}$ Dalmo Vieira Filho é arquiteto e atuou no processo de restauro das fortalezas catarinenses. Fora aluno de Cyro Lyra, na UFPR, e atuou como arquiteto na ARESTA durante as obras de restauro nas fortalezas catarinenses. Foi o primeiro diretor da divisão do Iphan em Santa Catarina.

${ }^{23}$ Maria de Lourdes de Souza, enfermeira, foi pró-reitora da Pró-Reitoria de Cultura e Extensão da Universidade Federal de Santa Catarina entre 1989 e 1992, tendo atuado no Projeto "Fortalezas da Ilha de Santa Catarina - 250 anos de História Brasileira".

${ }^{24}$ Para entender melhor a relação entre estes agentes sociais no processo de patrimonialização das fortalezas catarinenses, ver Pereira (2016) e Celso Martins; Armando Gonzaga (2017).

${ }^{25}$ Ao restaurarem estas fortalezas, estes agentes viam-se como que salvando estas estruturas do arruinamento e do desaparecimento, porém, atuando não apenas na preservação física destas construções, mas como se o restauro implicasse na preservação da própria História mediante a valorização destes bens culturais. Para estes agentes sociais, as ruínas das fortalezas catarinenses representavam mais que a degradação dos edifícios centenários; viam nas ruínas o descaso, a desvalorização e o não-reconhecimento da história catarinense e brasileira (PEREIRA, 2016).
} 
Celso Martins, quando rememora a sua participação nas obras de restauro das fortalezas catarinenses, na década de 1970: "Ninguém dava a menor bola para isso, a menor bola, essa que é a verdade. O prefeito não tinha interesse, a população não estava nem aí". ${ }^{26}$

Em 1983, Cyro Lyra foi entrevistado pela revista A construção: Região Sul, publicada no artigo "Porque e como Anhatomirim, ou a 'toca pequena do diabo', foi restaurada". O arquiteto apontava que a Fortaleza de Anhatomirim foi desativada na década de 1950, "quando já não representava nenhum interesse militar", retirando-se dali a guarnição da Marinha e "deixada aos cuidados de um encarregado".

Em 1955 já estava inteiramente deserta e apresentada um rápido processo de arruinamento.

"Enquanto isso, conta o arq. Cyro Lyra, os moradores do continente, como novos corsários, tomavam de assalto a fortaleza para saquear seus edifícios, deles arrancando portas e janelas, forros e soalhos, telas e peças sanitárias, deixando apenas as paredes, as cantarias e as pesadas vigas". ${ }^{27}$

Dalmo Vieira Filho faz considerações bastante semelhantes, em sua narrativa:

O que mais chamava a atenção era Anhatomirim pela sua impotência. Depois do tombamento, essa fortaleza foi desativada após a $2^{\circ}$ Guerra Mundial. Foi mantido ainda um vigia; quando ele se aposentou, ela foi abandonada e depredada pela população, que levou telhas, madeira, assoalho, tijolo, o que podia carregar da fortaleza abandonada. Conheço várias pessoas que ainda viram Anhatomirim com coberturas, mais ou menos entre a década de 50/60, quando ela ficou entregue à pilhagem. ${ }^{28}$

José La Pastina Filho, em entrevista a Celso Martins, rememora como foi possível restaurar boa parte das edificações com material original:

Nós comprávamos telhas Eternit de boa qualidade e percorríamos a região trocando-as por telhas capa e canal [...] Mesmo porque a população do entorno da ilha de Anhatomirim, nesses anos em que ela ficou abandonada, serviu-se de tudo aquilo como mina de material de construção". Tanto é que as esquadrias das edificações de Santa Cruz "tinham sido totalmente tiradas", assim como as telhas e madeiras, "era uma fonte de matéria prima". Muitas viagens depois, a bordo de uma caminhonete e seguidos transportes por lancha até a ilha, conseguiram reunir 20 mil telhas. "Foi um esforço

\footnotetext{
${ }^{26}$ LYRA, Cyro Corrêa. Restauração das fortalezas da Ilha de Santa Catarina. Entrevista concedida a Celso Martins. Florianópolis, outubro de 2015. [Gravação digital transcrita, acervo do autor]. Apud MARTINS; $\operatorname{GONZAGA}(2017$, p. 156)

${ }^{27}$ MOISÉS, Raquel. Porque e como Anhatomirim, ou a "toca pequena do diabo", foi restaurada. A Construção: Região Sul, n 177, 1983.

${ }^{28}$ FILHO, Dalmo Vieira. Julho de 1990. A entrevista na íntegra encontra-se transcrita no CD-Rom Fortalezas Multimídia (TONERA, 2001).
} 
muito grande. ${ }^{29}$

O discurso destes agentes sociais está para além da denúncia ao descaso do Estado para com o seu patrimônio, ou, da falta de investimento em políticas de preservação dos monumentos até aquele momento; é um lamento de que a sociedade catarinense, em geral, e, especialmente, as comunidades estabelecidas no entorno destas fortalezas, não souberam valorizar estes bens por não reconhecer naquelas ruínas o seu devido valor histórico.30

Tal valor histórico, por outro lado, não é dado, tampouco intrínseco a estes bens culturais: é construído a partir de uma dada concepção de história, que privilegia uma narrativa histórica em detrimento de outras, produto de uma seleção de sentidos e significados em detrimento de outros. A patrimonialidade destes bens se configura de forma a construir uma rede de adesões em torno destes monumentos entre aqueles que compartilham destes valores, sentidos e significados; ao mesmo tempo, são excluídos outros sujeitos, outras memórias, experiências - enfim, outras histórias.

\section{Que História é essa?}

Maria Cecília Londres Fonseca (2009, p. 108) afirma que "a noção do valor histórico adotada pelo SPHAN nos anos 1940 era balizada pela historiografia da época”. Também Delgado (2008) relaciona a prática do tombamento na construção do patrimônio nacional à historiografia:

O tombamento de edificações isoladas justifica-se, assim, a partir do conceito de monumento histórico: determinadas construções são consagradas como testemunhas da história e passam a incorporar a função de suscitar a rememoração do passado. Com isso, o conjunto dos bens tombados pelo Sphan constrói uma narrativa material "de pedra e cal" de determinada história do Brasil consagrada como a História nacional, cuja matriz discursiva foi produzida no Instituto Histórico e Geográfico Brasileiro (IHGB). (DELGADO, 2008, p. 104)

No caso das fortalezas catarinenses, encontramos paralelo com o Instituto Histórico e Geográfico de Santa Catarina (IHGSC), cuja matriz discursiva caracteriza-se como "uma História narrativa, baseada especialmente em fontes oficiais - mas, no caso de Santa Catarina,

\footnotetext{
${ }^{29}$ LA PASTINA FILHO, José. Restauração das fortalezas da Ilha de Santa Catarina. Entrevista concedida a Celso Martins. Florianópolis, outubro de 2015. [Gravação digital transcrita, acervo do autor]. Apud MARTINS; GONZAGA (2017, p. 75)

${ }^{30}$ Ressaltamos que este discurso sobre a ruína é tanto posterior quanto simultâneo ao trabalho de restauro das fortalezas; sendo assim, se constrói esta memória sobre o arruinamento e a não-valorização das fortalezas em um contexto em que estas já se encontravam (ou estavam para ser) recuperadas e valorizadas, de acordo com as concepções de História e patrimônio engendradas pelos agentes.
} 
também muitos em relatos de viajantes -, normalmente referenciada nos fatos políticos, cujos personagens são os chamados 'grandes homens"' (CAROLA, WOLFF, SILVA, 2011, p. 304).

As Fortaleza de Anhatomirim, da Ponta Grossa, de Ratones e o Forte de Santana foram inscritos no Livro do Tombo de Belas Artes e no Livro do Tombo Histórico em 24 de maio de 1938, passando a integrar a "coleção de bens da cultura material que deveriam expressar a 'memória nacional' ou a produção cultural 'mais autêntica' da nação, capaz, portanto, de narrar sua história e origem".31 Com esta prática, o SPHAN "investiu no projeto de construção da nação, consagrando uma história concreta, autenticando-a pela materialidade de um patrimônio histórico e artístico nacional apresentado". Trata-se, portanto, de uma dupla construção: ao mesmo tempo que o SPHAN seleciona determinadas construções como "testemunhas da história" isto é, para dar "materialidade à história", por outro lado há uma seleção de qual história estes bens testemunhariam, ou, materializariam (CHUVA, 2009, p. 206, 207).

O valor histórico atribuído às fortalezas catarinenses pelos agentes envolvidos no processo de patrimonialização destes bens advém desta concepção.32 A história materializada nas fortalezas catarinenses a partir do processo de patrimonialização destas é aquela História de Santa Catarina, vinculada à História do Brasil;33 Santa Catarina é inserida na "História da Nação" através dos grandes acontecimentos políticos e militares como a invasão espanhola em 1777 e a Revolução Federalista em 1894, eventos que tiveram as fortificações catarinenses como palco. O tombamento destas fortalezas perpassa o processo de construção de uma "memória nacional", que, aliado ao "contexto de nacionalização do Estado brasileiro", significou "impingir unidade, impedindo qualquer feição plural da nação" (CHUVA, 2009, p. 207).

A esta História, Nilton Mullet Pereira (2017, p. 228) chama de história maior, uma narrativa "estrutural, que recobre, em regra, tempos longos e descreve tempos contínuos e sequenciais, excluindo as descontinuidades e as diferentes alternativas que se apresentam a cada

\footnotetext{
${ }^{31} \mathrm{O}$ discurso sobre a origem inscreve Santa Catarina na memória histórica da Nação através destas fortalezas; a construção do sistema defensivo da Ilha de Santa Catarina é considerada pelos autores tradicionais da historiografia catarinense como um dos principais marcos de fundação do Estado - relacionando com a criação da capitania de Santa Catarina e com a vinda do brigadeiro Silva Paes (PEREIRA, 2016).

32 A matriz discursiva para esta concepção era produzida a partir do Instituto Histórico e Geográfico Brasileiro (IHGB) ou do Instituto Histórico e Geográfico de Santa Catarina (IHGSC), ao qual eram vinculados significativa parcela dos autores que trataram sobre estas fortalezas - dentre os quais, Oswaldo Rodrigues Cabral e Walter Piazza, que, posteriormente, integraram o corpo docente da Universidade Federal de Santa Catarina, quando da criação desta, em 1960 (CAROLA, WOLFF, SILVA, 2011, p. 304).

${ }^{33}$ Usamos História com letra maiúscula para denotar a vinculação à disciplina escolar ou acadêmica aos moldes do tradicionalismo apontado por Carola, Wolff e Silva (2011), como uma história que carrega no seu discurso de verdade e de oficialidade a pretensão de se colocar como a única história.
} 
momento"; uma narrativa "baseada na descrição de grandes arranjos estruturais e sistêmicos, que conduz a constituição de esquemas explicativos de uma época e de um período determinado"; uma história esquematizada em "períodos, em ciclos, todos dotados de uma lógica única".

A história maior se constitui como "parte de um processo complexo de construção de adesões, interpelações e constituições de subjetividades, que excluem e silenciam ao estabelecer parâmetros definitivos ao passado na forma de história". Essa narrativa da história maior se revela como história "limpa", depurada da desrazão, do inexplicável, dos acontecimentos que rompem com as lógicas e fazem fendas nas estruturas" (PEREIRA NM, 2017, p. 229, 233). É uma história linear, preenchida com datas e fatos em contínuo, destacando alguns poucos sujeitos que "fazem a história"; a história maior silencia e invisibiliza as memórias individuais, de grupos e de povos, que não são contempladas pela grande memória. Esta discussão nos aponta para as teses sobre o conceito de História do filósofo berlinense Walter Benjamin.

Benjamin constrói o seu conceito de história a partir de uma relação original entre materialismo histórico, messianismo judaico e romantismo, ${ }^{34} \mathrm{em}$ oposição às duas concepções dominantes da sua época, o historicismo e a história progressista. O filósofo berlinense critica a maneira como passado, presente e futuro se articulam nestas teorias, baseadas em uma concepção de tempo linear e homogêneo. ${ }^{35}$ Para ele, nem o passado nem o presente estão dados. Mate (2011, p. 92, 121-122) identifica dois tipos de passado na concepção benjaminiana: um passado presente e um passado ausente. O primeiro "está presente por direito próprio (é o passado dos vencedores)" - é deste passado que a história se ocupa, como "matéria que a hermenêutica elabora" e "caminho real por onde transitam as tradições"; o segundo é um passado malogrado, que não chegou até nós, que não chegou a ser, enfim, é o passado dos vencidos. Da mesma forma, o presente se manifesta de duas maneiras: como um presente "dado, o que chegou a ser e que temos diante de nós", como "história real", e como "presente só como possibilidade", isto é, como "aquilo que quis ser e foi malogrado".

Na concepção de história elaborado por Walter Benjamin, presente e passado não são pontos dispostos em uma reta, mas são pontos interativos como tempos de agora (Jetztzeit). A história "não é um continuum, no qual o passado causa o presente e este determina o futuro", mas sim um conjunto de "ideias fragmentadas, de conhecimentos perecíveis, já que estão

\footnotetext{
${ }^{34}$ Para uma discussão mais aprofundada sobre a relação entre materialismo histórico, messianismo judaico e romantismo, ver: Löwy (2005), Mate (2011), Žižek (2012), Paim, Pereira e Freire (2018).

${ }^{35}$ Recomendamos Gagnebin (1984), Mate (2011) e Löwy (2005) para uma discussão mais aprofundada a respeito deste assunto.
} 
submetidos a novas iluminações". Para ele, "a história deveria ser representada como um passado esmiuçado em imagens" (MATE, 2011, p. 114).

Benjamin (2012, p. 243) contesta a pretensão de reconstituir "toda a história", ou, a história "tal como de fato aconteceu" alegando que "articular historicamente o passado não significa conhecê-lo 'tal como ele de fato foi"'; articular historicamente o passado significa "apropriar-se de uma recordação como ela relampeja no momento do perigo", pois o passado "só se deixa capturar como imagem que relampeja irreversivelmente no momento de sua conhecibilidade".

Enquanto o modelo historiográfico do historicismo recomendava "ao historiador interessado em reviver uma época" que esquecesse "tudo o que se sabe sobre fases posteriores da história", Benjamin denunciava que este distanciamento faz com que o historiador estabeleça uma relação de empatia com os vencedores, pois "os que num momento dado dominam são os herdeiros de todos os que venceram antes. A empatia com o vencedor beneficia sempre, portanto, esses dominadores". Benjamin propunha um outro tipo de distanciamento: o historiador se distancia pois "ele não pode refletir sem horror" sobre a origem destes bens culturais, que "devem a sua existência não somente ao esforço dos grandes gênios que os criaram, mas também à servidão anônima dos seus contemporâneos" (BENJAMIN, 2012, p. 244).

Por isso, cultura e barbárie não lhe parecem opostas; pelo contrário, são duas faces da mesma moeda: "Nunca houve um documento da cultura que não fosse simultaneamente um documento da barbárie. E, assim como o próprio bem cultural não é isento de barbárie, tampouco o é o processo de transmissão em que foi passado adiante" (BENJAMIN, 2012, p. 244). Löwy (2005, p. 75) compreende que Benjamin apresenta cultura e barbárie como uma "unidade contraditória", e não como "dois polos que se excluem mutuamente, ou como etapas diferentes da evolução histórica":

A alta cultura não poderia existir sob a forma histórica sem o trabalho anônimo dos produtores diretos - escravos, camponeses ou operários - eles próprios excluídos do prazer dos bens culturais. Esses últimos são, portanto, "documentos da barbárie" uma vez que nasceram da injustiça de classe, da opressão social e política, da desigualdade, e porque sua transmissão é feita por massacres e guerras. [...] Em cada caso, a elite dominante se apropria - pela conquista, ou por meios bárbaros - da cultura anterior e a integra a seu sistema de dominação social e ideológico. A cultura e a tradição tornamse, assim, como saliente Benjamin em sua tese VI, 'um instrumento das classes dominantes"' (LÖWY, 2005, p. 78-79).

O historiador benjaminiano tem como tarefa "escovar a história a contrapelo" 
(BENJAMIN, 2012, p. 244); em outras palavras, "atentar para o desprezado pela história canônica, olhar o outro lado do espelho, fixar-nos no lado oculto da realidade", pois o historiador benjaminiano "não pode fazer da história uma escola de transmissão de violência" (MATE, 2011, p. 175). Este imperativo, para Löwy (2005, p. 74, 79), é carregado de um sentido histórico de "ir contra a corrente da versão oficial da história, opondo-lhe a tradição dos oprimidos"; significa “considerá-la do ponto de vista dos vencidos, dos excluídos, dos párias". Desta forma, "a história da cultura 'deve ser integrada à história da luta de classes"”.

Benjamin nos desafia a "desconfiar das leituras canônicas do passado". A história não deve ser mobilizada de modo ao passado legitimar o presente - esta é a história contada do ponto de vista os vencedores, a fim de justificar as suas próprias vitórias e a sua posição como dominadores. Benjamin propõe um movimento inverso, em que a interpretação do passado questione a "autoridade do dado presente", e, assim, o passado deixa de ser um "depósito de antiguidades do qual o presente lança mão para afirmar seus interesses" (MATE, 2011, p. 143).

O historiador benjaminiano se assemelha a um cronista para quem nada pode ser dado como perdido; todos os fatos históricos lhe interessam, tanto os grandes quanto os pequenos. Outros sujeitos compõem a cena, para além dos reis, dos papas, dos generais e dos comandantes, assim como outros fatos ganham importância, para além dos fatos políticos e militares - as batalhas, as guerras, os tratados, as leis, as coroações, as conquistas. Benjamin (2012, p. 244) olha a história a partir de baixo, assumindo o olhar dos que estão "prostrados no chão".

A memória aqui assume um papel fundamental, especialmente como memória coletiva dos vencidos. A memória traz para a ordem do dia expedientes que a História já dava por encerrados; ela se ocupa dos "não-fatos", do "passado que só foi e do qual já não há rastro"; por isso, "é capaz de ler a parte não escrita do texto da vida" (MATE, 2011, p. 164). Maria Carolina Bovério Galzerani (2008, p. 20, 21) infere que, para Benjamin, “a grande questão na reflexão sobre a memória não é propriamente aquilo que é possível rememorar, mas é saber lidar com o fantasma do esquecimento". Esta autora afirma que "para Benjamin, rememorar é um ato político, com potencialidades de produzir um 'despertar' dos sonhos, das fantasmagorias, para a construção das utopias"; neste sentido, "rememorar significa trazer o passado vivido como opção de questionamento das relações e sensibilidades sociais, existentes também no presente, uma busca atenciosa relativa aos rumos a serem construídos no futuro." O conceito de memória de Benjamin amplia a "dimensão de ser sujeito - tanto sob o ponto de vista social tanto sob o ponto de vista psicológico", pois traz em si a capacidade de "dinamizar a visão de produção de conhecimentos, entrecruzando diferentes espaços, diferentes temporalidades, 
diferentes sujeitos, diferentes visões do mundo".

A memória dos vencidos tem a capacidade de questionar as relações e sensibilidades sociais pois é identificada com este passado ausente; rememorar, neste sentido, é um ato político pois coloca em xeque a memória dos vencedores. É a memória que leva o historiador benjaminiano às ruínas do passado, para vasculhar, no meio dos escombros, vidas frustradas, isto é, possibilidades outras de vir a ser.

Tendo em vista todos esses elementos, não há outro jeito que concluir que não há um só documento de cultura que não seja também de barbárie. Ele não está dizendo que a cultura seja barbárie, mas que esta está aninhada no interior da cultura. Inclusive quando a cultura se apresenta como visão crítica da barbárie, tal e como ocorre em museus, unidades didáticas ou documentários televisivos, a barbárie espreita. Quando as exposições do sofrimento não levam a uma experiência compassiva, só se consegue acalmar a má consciência do espectador. A cultura dominante não pode impedir uma boa reportagem crítica, mas pode privá-la de seu aguilhão no mesmo momento em que a transmite. (MATE, 2011, p. 184)

A partir destas reflexões, apontamos para a possibilidade de uma outra abordagem do patrimônio cultural em que este não seja apenas o butim, mas seja compreendido como uma arena na qual se trava uma forma de luta contra a opressão, baseada na mobilização de ideias e sentimentos dos oprimidos. Faz-se necessário uma abordagem em que as histórias contadas a partir do patrimônio não sejam apenas as memórias dos vencedores, mas, também, as memórias e experiências dos vencidos. Estas memórias não devem ser consideradas apenas como outras histórias, e, muito menos, como ilustrativas; estas memórias questionam as vitórias dos dominadores, desestabilizam o presente estado de coisas e clamam por justiça.

As contribuições de Benjamin nos levam a uma série de questionamentos sobre as questões do patrimônio no Brasil, e, no presente caso, das fortalezas catarinenses: que tipo de experiência com a história se propõe através destes monumentos? As fortalezas são apresentadas como butim, como despojos, ou como meios em que é possível estabelecer uma experiência com o passado? Quais memórias são valorizadas neste processo? Quais histórias são contadas e como são contadas?

Quando afirmamos que a concepção de História articulada na preservação destes monumentos seleciona uma série de sentidos e significados em detrimento de outros, quais são estes outros valores? Quem são estes sujeitos que afirmamos serem excluídos deste processo? As narrativas aqui apresentadas estabelecem uma relação de empatia com os vencedores ou com os vencidos? A história das fortalezas catarinenses apresentada justifica o passado a partir 
do presente, ou nos oferece uma leitura do passado que contemple possibilidades de um outro presente?

A história materializada nestas fortalezas é uma história maior, que representa a memória das elites locais e nacionais, arraigada nos dispositivos institucionais. É uma história que consagra os valores, significados e memórias relacionados às elites e aos seus herdeiros a medida que se configura como uma memória do poder (CHAGAS, 2002). Esta história evoca usos destes espaços como unidades militares dentro de uma ordem política que se configura no período colonial e tem a sua continuidade no período imperial; é uma história que tem como personagens os militares de alta patente, governadores, presidentes de Província, altos funcionários.

Entretanto, podemos encontrar vidas frustradas em meio às ruínas restauradas das fortalezas. Existem outros passados a serem explorados, passados ausentes, malogrados, outras histórias que são silenciadas, esquecidas ou subalternizadas como de menor importância, como curiosidades, ou, como "estórias", "causos", "lendas". São as memórias e experiências da população que vive nas comunidades do entorno destas fortalezas; são os negros escravizados e os indígenas que serviram de mão de obra para construir estas fortificações; são os soldados que serviram nestas unidades, desde o século XVIII até meados do século XX, que viveram ali com as suas famílias; são os sujeitos adoentados que foram isolados nestes ambientes quando serviram de local de isolamento para doenças contagiosas, no século XIX; são aqueles que foram executados sumariamente na Fortaleza de Anhatomirim, durante a Revolução Federalista em 1894, entre outros.

Através dos usos dados a estes monumentos - especialmente o turismo - privilegia-se uma experiência com a história que reproduz estas narrativas já consagradas pela historiografia catarinense, popularizadas através da imprensa local, impressa ou audiovisual. Como vimos anteriormente, esta mesma imprensa noticia o impasse na Praia do Forte enviesadamente, colocando em pé de (pretensa) igualdade a UFSC e a comunidade. A intenção da UFSC é de que os moradores desta comunidade, da comunidade do Ratones, das praias de Governador Celso Ramos e outros frequentem as fortalezas apenas condição de visitantes; devem visitar as fortalezas para aprender, mas não como quem tem algo a ensinar.

Para viabilizar o restauro das fortalezas de Anhatomirim, Ratones e Ponta Grossa, a UFSC estabeleceu uma parceria com diversas instituições públicas, como a Companhia Catarinense de Águas e Saneamento (CASAN), as Centrais Elétricas de Santa Catarina (CELESC), a Companhia de Desenvolvimento do Estado de Santa Catarina (CODESC), o 
Departamento Autônomo de Turismo do Estado de Santa Catarina (DEATUR), o Escritório Catarinense de Planejamento Integrado (ESPLAN), a Secretaria Municipal de Turismo de Florianópolis (SETUR), a Superintendência de Desenvolvimento da Região Sul (Sudesul) e as Telecomunicações de Santa Catarina (TELESC), e contou também com diversas empresas privadas, como a Cassol, Coca-Cola, Bamerindus, Koerich, WEG, Souza Cruz, BESC, Inplac, Portobello, Pedrita, em fins dos anos 1980 (PEREIRA, 2016). Hoje, a universidade, em um esforço de ampliar o trabalho que tem desenvolvido nestes espaços, propõe a criação de um "Plano de Ação para Integração Acadêmica", proposta que caminha para a construção de uma Agenda Propositiva que enumera como envolvidos os "docentes, discentes, núcleos de pesquisa, laboratórios e grupos de estudos" desta mesma universidade, para que "tenham a participação efetiva por meio de ideias, propostas, sugestões e parcerias que possibilitem a vinculação do Projeto Fortalezas da Ilha de Santa Catarina com as atividades acadêmicas de extensão da UFSC e sua inter-relação com o ensino e a pesquisa" (UFSC, 2014, p. 52). Em nenhum momento as comunidades vizinhas são elencadas como possíveis parceiras da universidade nesta relação de ensino-pesquisa-extensão.

Mas como poderiam estes ser cotados para parceria se - segundo a narrativa dos arquitetos citados - sua maior contribuição foi a depredação destas fortalezas? Na leitura dos agentes sociais mencionados, o maior ato de barbárie - contraposto à cultura - teria sido praticado pelos moradores das comunidades do entorno destas fortalezas, que, não apenas não valorizaram estes espaços, como se apropriaram das telhas, madeiramento, janelas, e outros materiais ali encontrados como uma "fonte de matéria prima", nas palavras de La Pastina. Estes atos seriam a expressão da falta de reconhecimento e da não-valorização destes bens culturais pela sociedade, do abandono e do descaso por parte do Estado.

As narrativas construídas sobre estes sujeitos e estas comunidades inviabilizam a participação destes no processo de patrimonialização destes bens culturais; estes sujeitos não são reconhecidos como sujeitos históricos, devido à concepção de história articulada, e, assim, nega-lhes o estatuto de herdeiros deste patrimônio. As fortalezas catarinenses, como documentos da cultura, podem ser instrumentalizadas como documentos de barbárie.

Ao problematizarmos o olhar dos agentes sociais envolvidos neste processo de patrimonialização, vemos que estes se identificam com os valores, significados e sentidos consagrados na patrimonialização destes bens, conforme as concepções de história e patrimônio presentes naquele contexto (PEREIRA, 2016). Entretanto, a partir das transformações no campo do patrimônio no Brasil, sobretudo nas últimas décadas, vimos a "ampliação da noção 
de patrimônio histórico para a de patrimônio cultural", uma noção que "rompe com a visão elitista que considerava apenas objeto de preservação cultural as manifestações de classes historicamente dominantes" e passa a incorporar "os registros e modos de expressar a cultura de diferentes grupos étnicos e sociais que contribuíram e contribuem para a formação da sociedade brasileira" (PEREIRA; ORIÁ, 2012, p. 166). A dimensão imaterial do patrimônio está presente, também, nos bens materiais de "pedra e cal" - como são as fortalezas catarinenses - e nos levam a uma nova abordagem para com o patrimônio onde este é tomado como processo permanente em vez de produto final. Se é um processo permanente, significa que podemos, a partir da abordagem pedagógica do patrimônio, (re)descobrir uma pluralidade de memórias em torno dos bens culturais e valorizá-las da mesma forma que aquelas já reconhecidas, e, desta forma, não apenas estabelecer uma outra relação com os bens culturais mas também com estes outros sujeitos históricos do passado e do presente, construindo outras narrativas históricas. Trata-se de uma leitura à contrapelo do patrimônio que evidencia as "imbricações do passado no presente, com acenos de um redesenho de futuros possíveis" (HADLER, 2015, p. 231).

Estas questões implicam uma compreensão outra do "vandalismo" dos moradores do entorno das fortalezas, para além das questões legais envolvidas. A retirada de "matéria prima" dos edifícios em ruínas das fortalezas nos revelam uma não-adesão à patrimonialidade conferida a estes bens culturais através do tombamento. Estes sujeitos não se identificavam com o valor histórico eleito, não lhes representava; em outras palavras, não era a sua história.36

Neste sentido, é importante atentar para as considerações dos irmãos Alves da Luz, veiculadas pelo jornal Notícias do Dia: Ivânio afirma que "quando o Exército chegou, já havia famílias aqui", expressando o sentimento de que "os antigos moradores da área é que foram invadidos quando surgiram as fortificações", no século XVIII; Neusa, quando denuncia que a “Universidade explora os turistas ao cobrar R\$ 8 pela entrada na fortificação", e que "está convencida de que 'o pessoal de Jurerê' quer tomar conta da área". Para estes moradores da comunidade da Praia do Forte, o "inimigo não tem cessado de vencer" (BENJAMIN, 2012, p. 243): ora o Exército, ora a Universidade Federal de Santa Catarina, ora os empresários ligados ao setor imobiliário. A preservação do patrimônio cultural parece-lhes mais uma forma de invasão dos vencedores. A narrativa que estes sujeitos nos oferecem é a de perpetuação do Estado de exceção, conforme expressão de Benjamin (2012), enquanto a UFSC, bem como os

\footnotetext{
36 Importante ressaltar que a Fortaleza de Anhatomirim permaneceu ativa até a década de 1950, enquanto as demais fortalezas já tinham sido desativadas no início do século XX, pois tornaram-se obsoletas diante das novas tecnologias bélicas.
} 
agentes sociais a ela vinculados, apresentam uma narrativa de triunfo.

\section{Considerações Finais}

Partilhamos da observação de Tonera (2008, p. 07) de que a "difusão cultural” e a "democratização da informação e do conhecimento" sobre as fortalezas "são os instrumentos que podem efetivamente consolidar os bons resultados alcançados até o momento e garantir a preservação destes monumentos", aliados às "obras de restauração" e às "ações de revitalização empreendidas ao longo dos últimos anos" para assegurar o "processo de valorização gradual e crescente das fortificações militares". Acrescentamos que é preciso passar da democratização para a pluralização do acesso às fortalezas; é preciso reconhecer outros saberes, outras memórias e outras experiências vinculadas a estes bens culturais, a fim de que os moradores das comunidades próximas a estas fortalezas também se reconheçam como herdeiros do patrimônio - podendo, assim, gerar novas adesões em torno destes bens culturais.

Assim como Tonera (2005, p. 06), reconhecemos a importância de criar uma "equipe multidisciplinar e interinstitucional que possa equacionar as múltiplas questões relacionadas às fortificações", que, além do desenvolvimento de uma "pesquisa histórica e documental, conservação e manutenção, gerenciamento administrativo, visitação turística, divulgação e difusão", possam agregar as comunidades do entorno das fortalezas na gestão destes bens culturais. Assim, nestas "múltiplas questões" estarão inclusas, também, as questões próprias destas comunidades tradicionais. Desta forma, estes sujeitos deixarão de ser meros frequentadores destes espaços para serem reconhecidos como herdeiros legítimos destes espaços, tanto quanto os herdeiros já reconhecidos; não mais apenas alvo desta divulgação e difusão dos saberes produzidos sobre as fortalezas, mas, também, difusores dos seus saberes sobre estes bens. Assim, será possível engendrar novas experiências educativas com o patrimônio, a partir do uso social da memória.

A partir de Galzerani (2013, p. 96), acreditamos que é possível que os sujeitos transformem os 'patrimônios oficiais em 'lugares de memória' - concebidos como materialização de uma pluralidade de imagens e de visões de mundo, imbricando experiências vividas às reflexões histórico-educacionais". Estas experiências - sejam estas formais ou nãoformais - devem permitir aos sujeitos construírem, ressignificarem e reelaborarem sentidos para os bens patrimonializados mediante uma relação horizontal, o que implica outras relações de poder.

Apostamos que as fortalezas catarinenses podem ser espaços plurais, de diálogos 
interculturais, a partir de uma ampliação da noção de patrimônio cultural no uso e na gestão destes bens por parte da Universidade Federal de Santa Catarina através de parcerias com as comunidades tradicionais, com as escolas locais, e outros agentes sociais que venham a somar neste enfoque de efetiva preservação e valorização do patrimônio cultural, em suas múltiplas dimensões.

\section{Referências Bibliográficas}

ABERTURA da Temporada de Verão nas Fortalezas da UFSC com atrações culturais e entrada gratuita. Notícias da UFSC [online], 31 out 2017. Disponível em: $<$ http://noticias.ufsc.br/2017/10/abertura-da-temporada-de-verao-nas-fortalezas-da-ufsc-comatracoes-culturais-e-entrada-gratuita/>. Acesso em: 09 jan 2018.

BENJAMIN, Walter. Magia e técnica, arte e política: ensaios sobre literatura e história da cultura. $8^{a}$ ed. rev. São Paulo: Brasiliense, 2012. (Obras Escolhidas v.1)

CAROLA, Carlos Renato; WOLFF, Cristina Scheibe; SILVA, Janine Gomes. A historiografia de Santa Catarina: olhares sobre os últimos 50 anos. In.: GLEZER, Raquel et al. Do passado para o futuro: edição comemorativa dos 50 anos da Anpuh. São Paulo: Contexto, 2011.

CHAGAS, Mario. Memória e poder: dois movimentos. Cadernos de Museologia, Lisboa, v. 19, n. 19, p. 43-81, 2002.

CHUVA, Márcia Regina Romeiro. Os arquitetos da memória: sociogênese das práticas de preservação do patrimônio cultural no Brasil (anos 1930-1940). Rio de Janeiro: Editoria UFRJ, 2009.

DELGADO, Andréa Ferreira. Configurações do campo do patrimônio no Brasil. in: BARRETO, Euder et al (Orgs.). Patrimônio Cultural \& Educação Patrimonial. Goiânia: Secretaria de Educação, 2008.

FORTALEZA de São José da Ponta Grossa terá atrações especiais no domingo em Florianópolis. Notícias do Dia, online, 31 out 2017. Disponível em: $<$ https://ndonline.com.br/florianopolis/noticias/fortaleza-de-sao-jose-da-ponta-grossa-teraatracoes-especiais-no-domingo-em-florianopolis>. Acesso em: 09 jan 2018.

GALZERANI, Maria Carolina Bovério. Memória Tempo e História: perspectivas teóricometodológicas para pesquisa em ensino de história. Cadernos do CEOM (UNOESC), Chapecó, v. 28, p. 15-30, 2008.

GALZERANI, Maria Carolina Bovério. Práticas de ensino em projeto de educação patrimonial: a produção de saberes educacionais. Pro-Posições, v. 24, n. 1 (70), p. 93-107, 2013.

HADLER, Maria Silvia Duarte. Cidade e ensino de História. In.: ZAMBONI, E., GALZERANI, M.C.B.; PACIEVITCH, C. (Orgs.). Memória, sensibilidades e saberes. Campinas: Editora Alínea, 2015. 
IMPASSE na fortaleza de São José da Ponta Grossa. Jurerê. Ninguém tem coragem de fazer a demolição de construções irregulares pedida pela Justiça no Norte da Ilha. Notícias do Dia [online], 11 ago 2013. Disponível em: <https://ndonline.com.br/florianopolis/noticias/impassena-fortaleza-de-sao-jose-da-ponta-grossa>. Acesso em: 09 jan 2018.

LÖWY, Michael. Walter Benjamin: aviso de incêndio. Uma leitura das teses "Sobre o conceito de história”. São Paulo: Boitempo, 2005.

MACHADO, Rosangela Maria de Melo. Fortalezas da Ilha de Santa Catarina: um panorama. Florianópolis: Editora da UFSC, 1992.

MARTINS, Celso; GONZAGA, Armando Luiz. Memórias das Fortalezas: Ilha de Santa Catarina. No meio do caminho havia um Armando. Florianópolis: Bernúncia, 2017.

MATE, Reyes. Meia-noite na história: comentários às teses de Walter Benjamin "Sobre o conceito de história”. São Leopoldo (RS): Ed. UNISINOS, 2011.

PEREIRA, Júnia Sales. ORIÁ, Ricardo. Desafios teórico-metodológicos da relação Educação e Patrimônio. Resgate, v. 20, n. 23, 2012, p. 161-171.

PAIM, Elison Antonio; PEREIRA, Pedro Mülbersted; FREIRE, Ana Paula da Silva. Porque dialogar com experiências e memórias na acepção de Walter Benjamin ou a modo de apresentação. In.: PAIM, E. A.; PEREIRA, P. M.; FREIRE, A. P. S. (Orgs). Diálogos com Walter Benjamin: memórias e experiências educativas. Florianópolis: NUP/CED/UFSC, 2018, p. 17-35.

PEREIRA, Nilton Mullet. Ensino de História e resistência: notas sobre uma história menor. In.: PAIM, Elison Antonio (Org.). Patrimônio cultural e escola: entretecendo saberes. Florianópolis: NUP/CED/UFSC, 2017.

PEREIRA, Pedro Mülbersted. O processo de patrimonialização de fortaleza de Santa Cruz de Anhatomirim: discursos, restauro, usos (1970-1992). 1 v. Dissertação (Mestrado) Universidade Federal de Santa Catarina, Centro de Ciências da Educação, Programa de PósGraduação em Educação, Florianópolis, 2016.

TONERA, Roberto. Fortalezas Multimídia: Anhatomirim e mais centenas de fortificações no Brasil e no mundo. Florianópolis: UFSC, FAPEU, 2001. [CD-ROM]

TONERA, Roberto. O Sistema Defensivo da Ilha de Santa Catarina - Brasil: Criação, Abandono e Recuperação. Seminario Regional De Ciudades Fortificadas, I, 2005, Montevideo. Atas Virtuais, p. 2. Disponível em: <http://tinyurl.com/beaoldg>. Acesso em: nov. 2012.

UNIVERSIDADE Federal de Santa Catarina [UFSC]. Plano de Desenvolvimento Institucional 2015 a 2019. Florianópolis: UFSC, 2014.

ŽIŽEK, Slavoj. Vivendo no fim dos tempos. São Paulo: Boitempo, 2012. 